\title{
Factors Analysis Related to the Completeness of Providing Basic Immunization in Infant Aged 12 Months
}

\author{
Hannik Rahmaningrum ${ }^{1}$, Harmayetty ${ }^{1}$, Deni Yasmara ${ }^{1}$, Ilya Krisnana ${ }^{1}$ \\ Faculty of Nursing, Universitas Airlangga, Surabaya, Indonesia, Jl. Mulyorejo, Mulyorejo, Surabaya, Kota SBY, \\ Jawa Timur 60115, Universitas Airlangga Kampus C
}

\begin{abstract}
Background: The highest number of children with incomplete immunizations in Indonesia is five provinces in Java. During 2015, diphtheria cases in Blitar District, East Java reached 44 cases. However, in 2016, there was an increase with the discovery of 49 infants affected by diphtheria and spread in several districts and obtained the number of 12-month-old infants who did not get complete immunizations of 47 infants.

Aim: The purpose of this study analyzed the factors related to the completeness of basic immunization for 12-month-old infants.

Method: This study was a quantitative study with cross sectional approach. The study was conducted on mothers who have 12-month-old infants by filling out the questionnaires about the relationship of independent variables, namely knowledge and attitudes of the mother, family support and health workers support as well as the dependent variable, namely the completeness of basic immunization. Total respondents were 46 people. Data were analyzed using the Chi Square test to determine the relationship between independent and dependent variables and logistic regression statistical tests to find out the dominant variables related to the completeness of basic immunization.
\end{abstract}

Results: There was a relationship between maternal knowledge $(p=0,000)$, maternal attitudes $(p=0,000)$, family support $(p=0,000)$, and health workers support $(p=0,000)$ and the completion of basic immunization. The dominant factor related to the completeness of basic immunization was knowledge.

Conclusion: Knowledge, attitude, family support, and health workers support have a significant relationship with the completion of basic immunization.

Keywords: immunization, knowledge, attitude, family support, health workers support

\section{Introduction}

Basic immunization is the provision of early immunization for infants up to one year old to reach immune levels above the protection threshold. It means that if one day exposed to the disease, they would not be sick or only experience mild illness. The purpose of immunization in general reduces morbidity, mortality, and disability due to disease that can be prevented by

\section{Corresponding author : \\ Harmayett \\ E-mail: harmayetty123@gmail.com}

immunization (PD3I). In addition, other goals are the achievement of Universal Child Immunization (UCI) targets as determined, the elimination of PD3I such as tetanus, polio, measles, etc. and the implementation of safe immunization and management of medical waste (safety injection practice and waste disposal management) $)^{1,2}$.

World Health Organization (WHO) in 2011 mentioned 10 facts of serious diseases which become a global burden; one of them is a disease that can be prevented by immunization (PD3I). WHO noted that there are still 18.7 billion infants who do not get basic immunization. The highest number of children with 
incomplete immunizations in Indonesia is five provinces on Java Island (55.3\% of the national figure), namely East Java with 150,569 children, West Java with 180,788 children, Central Java with 199,030 children, Banten with 201,087 children and DKI Jakarta with 154,786 children $^{3-5}$.

One indicator of the immunization program success is the achievement of Universal Child Immunization (UCI). The achievement of UCI is a picture of immunization coverage in infants (0-11 months) nationally to the village level. WHO and UNICEF determined that immunization coverage indicator was $90 \%$ at the national level and $80 \%$ in all districts. In Indonesia, Basic Immunization is still $86.8 \%$ and Universal Child Immunization (UCI) is still $82.9 \%$. Some disease outbreaks that occur in several provinces in Indonesia are caused by diseases that should be prevented by immunization. In recent years, there have been cases of "re-emerging disease" due to measles and diphtheria in several provinces in Indonesia ${ }^{6}$.

The theory of Lawrence Green (1980) stated that a person's health is influenced by 2 main factors namely behavioral factors (behavior causes) and factors outside of behavior (non-behavior causes). A person's behavior factors are influenced by three factors, namely predisposing factors, enabling factors, and reinforcing factors. Predisposing factors consist of the level of knowledge, attitudes, education, perception, beliefs, socio-economic status, and age. The enabling factor consists of health service facilities that have the characteristics of availability, can be accessed, can be accepted, and can be reached. The last is the reinforcing factors consist of family support, health worker support, family support, health care support, and community figure support. The factors affecting health above need to be explored further, especially in relation to the completeness of basic immunization in infants aged 12 months ${ }^{7,8}$.

\section{Method}

This study was a quantitative research with analytical survey with cross sectional approach. The population in this study was mothers who had a 12-month-old infant in the working area of the Kademangan Health Center in Blitar, East Java, Indonesia. The sample was determined by calculating the formula, thus as many as 46 respondents were obtained. In this study, the sample was all mothers who have a 12-month-old infant with immunizations that was not on schedule.

Criteria for inclusion of respondents were: 1 . Willing to be a research respondent, 2. Can read and write, and 3. Mothers who have babies aged 12 months. However, the respondents' exclusion criteria were: 1 . Not willing to be a research respondent, 2. Cannot read and write, 3 . Mothers who have infants over 12 months.

The study was conducted on mothers who have 12-month-old infants in the working area of the Kademangan Health Center in Blitar Regency with a questionnaire containing the relationship of mother's knowledge, mother's attitude, family support and support of health workers with the completion of basic immunization. Sampling was done by purposive sampling technique. The dependent variable in this study was the completeness of basic immunization for infants aged 12 months. The independent variables in this study were the factors that influence the completeness which consists of maternal knowledge, maternal attitude, family support, and health workers support. The results of the validity and reliability test on the results of the questionnaire revealed that all questions were valid and reliable. The next data was taken by visiting one by one respondent's house. The analysis in this study included unvaried analysis, bivariate analysis using the Chi Square test with a degree of significance $\alpha<0.05$, and multivariate analysis.

\section{Result}

\section{Respondent Characteristic}

Table below showed the distribution respondent result based on age, last education, and job. 
Table 1 : Respondent Characteristic

\begin{tabular}{|l|l|}
\hline Respondent Characteristic & $\%$ \\
\hline Age & 10,9 \\
\hline $17-25$ & 80,4 \\
\hline $26-35$ & 8,7 \\
\hline $36-45$ & 100 \\
\hline Total & \\
\hline Last Education & 71,7 \\
\hline JHS & 26,1 \\
\hline SHS & 2,2 \\
\hline Freshgraduate & 100 \\
\hline Total & \\
\hline Job & 89,1 \\
\hline House Wives & 4,4 \\
\hline Farmer & 6,5 \\
\hline Staff & 6,7 \\
\hline Total & \\
\hline
\end{tabular}

Knowledge, Attitude, Family Support, Health Workers Support, and Completeness of providing Immunization Level

The level of some characteristic will explain in the below table.

Table 2 : Knowledge, Attitude, Family Support, Health Workers Support, and Completeness of providing Immunization Level

\begin{tabular}{|c|c|c|}
\hline Measured Variables & Category & $\%$ \\
\hline \multirow{3}{*}{ Knowledge } & Good & 52 \\
\hline & Sufficient & 15 \\
\hline & Less & 33 \\
\hline \multicolumn{2}{|l|}{ Total } & 100 \\
\hline \multirow{2}{*}{ Attitude } & Negative & 43 \\
\hline & Positive & 57 \\
\hline \multicolumn{2}{|l|}{ Total } & 100 \\
\hline \multirow{2}{*}{ Family Support } & Get support & 67 \\
\hline & Do not get support & 33 \\
\hline \multicolumn{2}{|l|}{ Total } & 100 \\
\hline \multirow{2}{*}{ Health Workers Support } & Get Support & 61 \\
\hline & Do not get support & 39 \\
\hline \multicolumn{2}{|l|}{ Total } & 100 \\
\hline \multirow{2}{*}{ Health Workers Support } & Complete & 63 \\
\hline & Incomplete & 37 \\
\hline \multicolumn{2}{|l|}{ Total } & 100 \\
\hline
\end{tabular}


The Relationship between Knowledge and Completeness of providing basic Immunization

There were relationship between maternal knowledge and the completeness of providing basic immunization in infants aged 12 months.

Table 3 : The Relationship between Knowledge and Completeness of providing basic Immunization

\begin{tabular}{|c|c|c|c|c|c|c|c|}
\hline \multirow{3}{*}{ Knowledge } & \multicolumn{4}{|c|}{ Completeness of providing basic Immunization } & \multirow{2}{*}{\multicolumn{2}{|c|}{ Total }} & \multirow{3}{*}{$\begin{array}{l}P \\
\text { value }\end{array}$} \\
\hline & \multicolumn{2}{|c|}{ Complete } & \multicolumn{2}{|c|}{ Incomplete } & & & \\
\hline & $\mathbf{f}(\mathbf{x})$ & $\%$ & $\mathbf{f}(\mathbf{x})$ & $\%$ & $\mathbf{f}(\mathbf{x})$ & $\%$ & \\
\hline Good & 24 & 52,2 & 0 & 0 & 24 & 52,2 & \\
\hline Enough & 4 & 8,7 & 3 & 6,5 & 7 & 15,2 & \\
\hline Less & 1 & 2,2 & 14 & 30,4 & 15 & 32,6 & \\
\hline Total & 29 & 63,1 & 17 & 36,9 & 46 & 100 & \\
\hline
\end{tabular}

The Relationship between Attitude Level and Completeness of providing basic Immunization

There were relationship between maternal attitude and the completeness of providing basic immunization in infants aged 12 months.

Table 4 : Attitude Level and Completeness of providing basic Immunization

\begin{tabular}{|c|c|c|c|c|c|c|c|}
\hline \multirow{3}{*}{ Attitude } & \multicolumn{4}{|c|}{ Completeness of providing basic Immunization } & \multirow{2}{*}{\multicolumn{2}{|c|}{ Total }} & \multirow{3}{*}{$\begin{array}{l}P \\
\text { value }\end{array}$} \\
\hline & \multicolumn{2}{|c|}{ Complete } & \multicolumn{2}{|c|}{ Incomplete } & & & \\
\hline & $f(x)$ & $\%$ & $f(x)$ & $\%$ & $f(x)$ & $\%$ & \\
\hline Positive & 24 & 52,2 & 2 & 4,3 & 26 & 56,5 & \\
\hline Negative & 5 & 10,9 & 15 & 32,6 & 20 & 43,5 & 0.000 \\
\hline Total & 29 & 63,1 & 17 & 36,9 & 46 & 100 & \\
\hline
\end{tabular}

The Relationship between Family Support Level and Completeness of providing basic Immunization

There were relationship between family support and the completeness of providing basic immunization in infants aged 12 months. 
Table 5 : The Relationship between Family Support Level and Completeness of providing basic Immunization

\begin{tabular}{|c|c|c|c|c|c|c|c|}
\hline \multirow{3}{*}{ Family Support } & \multicolumn{4}{|c|}{ Completeness of providing basic Immunization } & \multirow{2}{*}{\multicolumn{2}{|c|}{ Total }} & \multirow{3}{*}{$\begin{array}{l}P \\
\text { value }\end{array}$} \\
\hline & \multicolumn{2}{|c|}{ Complete } & \multicolumn{2}{|c|}{ Incomplete } & & & \\
\hline & $f(x)$ & $\%$ & $f(x)$ & $\%$ & $f(x)$ & $\%$ & \\
\hline Support & 26 & 56,6 & 5 & 10,7 & 31 & 67,4 & \\
\hline Do not Support & 3 & 6,6 & 12 & 26,1 & 15 & 32,6 & 0.000 \\
\hline Total & 29 & 63,2 & 17 & 36,8 & 46 & 100 & \\
\hline
\end{tabular}

The Relationship between Health Workers Support Level and Completeness of providing basic Immunization

There were relationship between health workers support and the completeness of providing basic immunization in infants aged 12 months.

Tabel 6 : The Relationship between Health Workers Support Level and Completeness of providing basic Immunization

\begin{tabular}{|c|c|c|c|c|c|c|c|}
\hline \multirow{3}{*}{ Health Workers Support } & \multicolumn{4}{|c|}{ Completeness of providing basic Immunization } & \multirow{2}{*}{\multicolumn{2}{|c|}{ Total }} & \multirow{3}{*}{$\begin{array}{l}P \\
\text { value }\end{array}$} \\
\hline & \multicolumn{2}{|c|}{ Complete } & \multicolumn{2}{|c|}{ Incomplete } & & & \\
\hline & $f(x)$ & $\%$ & $\mathbf{f}(\mathbf{x})$ & $\%$ & $\mathbf{f}(\mathbf{x})$ & $\%$ & \\
\hline Support & 25 & 54,3 & 3 & 6,6 & 28 & 60,9 & \\
\hline Do not Support & 4 & 8,7 & 14 & 30,4 & 18 & 39,1 & 0.000 \\
\hline Total & 29 & 63 & 17 & 37 & 46 & 100 & \\
\hline
\end{tabular}

\section{Discussion}

Based on data analysis using the Chi Square test, it was concluded that there was a relationship between maternal knowledge and the completeness of basic immunization in 12-month-old infants. The results of this study were consistent with research conducted by Odusanya (2008) which showed that maternal knowledge about immunization $(\mathrm{p}=0.006)$ was significantly related to immunization coverage. Maternal knowledge referred to what is known by mothers about complete basic immunization which included the type of complete basic immunization, diseases that can be prevented by immunization, immunization schedule, the number of doses given, and the benefits of immunization. People who are highly knowledgeable tended to have a better mindset so they try to apply a healthy lifestyle behavior ${ }^{1,9}$.

The results of this study differed from the results of the study of Astrianzah (2011) which examined that there was no relationship between the level of maternal knowledge and the status of complete basic immunization in infants $(\alpha=1,000)$. In this study, knowledge was everything that was known or answered 
by respondents about complete basic immunization in infants including the notion of immunization, benefits of immunization, type of immunization, and timing of immunization in infants. Knowledge was divided into three categories, namely good, sufficient, and less knowledge. Maternal knowledge about the completeness of basic immunization provision found that the majority of respondents' knowledge in the good category was 24 respondents, sufficient categories were 7 respondents, and less knowledge categories were 15 respondents. A person's knowledge was influenced by several factors, including age, education, occupation, interests, experience, culture, and information.

Based on data analysis using the Chi Square test, it was concluded that there was a relationship between maternal attitudes and the completeness of basic immunization for 12-month-old infants. The results of this study were consistent with Isnaini's research (2011) which stated that there was a significant relationship between maternal attitudes and compliance with basic immunization for infants. The formation of attitudes was based on the ability to think to understand and explore the completeness of basic immunization. Positive attitude of a mother, who has formed, can have a good impact on the basic immunization status of their children. On the other hand, if the maternal attitude was negative towards giving immunization, it can have a negative impact on the child's immunization status. The results of this study differed from studies conducted by Conscience (2013) that there was no relationship between maternal attitudes and the completeness of children's basic immunizations with a value of $\mathrm{p}=0.671 .25^{10}$.

According to the data, the attitude of the respondents in the statement of immunization to infants did not have to be in accordance with the specified schedule, there were respondents who answered agree. For the statement of each complete basic immunization can be done at health service, health center, midwife practice, or doctor's practice. There were respondents who answered disagree. In addition, in the statement of the frequency of giving complete basic immunizations to 12-month-old infants was 12 times, many respondents answered less agree as many as 16 respondents. From the results of the study, it can be illustrated that there were still negative attitudes of mothers about the statements above. In this case, maternal knowledge was very important. If mother has less knowledge about basic immunization, then maternal attitude will be negative, hence, her child was not given complete immunization.

Based on data analysis using the Chi Square test, it was concluded that there was a relationship between family support and the completeness of basic immunization for infants aged 12 months. The results of this study were in accordance with the study of Giantiningsih et al (2013) that the Chi Square Test results obtained exact value with $\mathrm{p}$ value of $0.204<0.05$. This examined about the relationship between the role of the family and the completeness of basic immunization in infants aged 1012 months. The results of this study differed from studies conducted by Gunawan (2009) which stated that there was no significant relationship between family support and the administration of Hepatitis B 0-7 immunization to infants. The best family support in this study lies in the domain of assessment which included families listening to the complaints of mothers when having difficulties in providing immunizations, families caring about maternal fears about the side effects of giving immunizations to their babies, and families always involving mothers in making decisions for provide complete immunization ${ }^{11}$.

Based on data analysis using the Chi Square test, it can be concluded that there was a relationship between health worker support and completeness of basic immunization for 12-month-old infants. The results of this study were in accordance with the research of Jusuf (2015) using the Chi Square test $p$ value $=0.031<\alpha=$ 0.05. 28 The results of this study differed from research conducted by Yahiji (2015) which revealed there was no relationship between the health profession support and complete basic immunization with $\mathrm{p}$ value of 0.580 . Health behavior of a person or community was also determined by the presence or absence of health information. The results of this study were obtained by mothers who said they had received counseling about basic immunization from health workers as many as 33 respondents. This depicted that the majority of respondents had received information or information from health workers, so it can be concluded that the factors that encourage mothers to immunize their infants because of the support of health workers ${ }^{12,13}$.

The dominant factor related to the completeness of basic immunization based on multivariate statistical 
tests was knowledge. The results of this study were supported by Tampemawa's study (2015) which mentioned that the most dominant variable influencing the immunization status of children aged 12-24 months was maternal knowledge. In this study, mothers with good knowledge showed higher completeness of basic immunization rates than mothers with less knowledge. Based on the logistic regression statistical tests that have been carried out, there was a 39.9 times greater risk to immunize their infants in mothers who have good knowledge about immunization compared with less knowledge. This was in line with Notoatmodjo (2010) which stated that a person's actions on health problems will basically be influenced by one's knowledge of the problem $^{14,15}$.

\section{Concusion}

There were relationship between maternal knowledge, maternal attitude, family support, and health workers support and completeness of providing basic immunization in infants aged 12 months. Health dominant factors that were related to completeness of providing basic immunization were maternal knowledge.

Ethical Clearance: Taken from the Faculty of Nursing, Universitas Airlangga, Surabaya committee, with the number "212-KEPK".

Source of Funding: The research was funded by author.

Conflict of Interest: There is no conflict of interest

\section{References}

1. Odusanya OO, Alufohai EF, Meurice FP, Ahonkhai VI. Determinants of vaccination coverage in rural Nigeria. BMC Public Health. 2008;8(1):381.

2. Timur DKPJ. Profil Kesehatan Provinsi Jawa Timur 2012. Surabaya Dinas Kesehat Provinsi Jawa Timur. 2013;

3. Organization WH. Annual Report 2014. 2015;

4. Wardle J, Frawley J, Steel A, Sullivan E. Complementary medicine and childhood immunisation: a critical review. Vaccine. 2016;34(38):4484-500.
5. Indonesia KKR. Profil Kesehatan Indonesia 2012. Jakarta Kementrian Kesehat Republik Indones. $2013 ; 222$.

6. Weiner JL, Fisher AM, Nowak GJ, Basket MM, Gellin BG. Childhood immunizations: first-time expectant mothers' knowledge, beliefs, intentions, and behaviors. Am J Prev Med. 2015;49(6):S42634.

7. Girard AW, Olude O. Nutrition Education and Counselling Provided during Pregnancy : Effects on Maternal, Neonatal and Child Health Outcomes. 2012;26:191-204.

8. Green LW, Kreuter MW, Deeds SG, Partridge KB, Bartlett E. Health education planning: a diagnostic approach. 1980;

9. Corben P, Leask J. To close the childhood immunization gap, we need a richer understanding of parents' decision-making. Hum Vaccin Immunother. 2016;12(12):3168-76.

10. MacDonald NE, Harmon S, Dube E, Steenbeek A, Crowcroft N, Opel DJ, et al. Mandatory infant \& childhood immunization: Rationales, issues and knowledge gaps. Vaccine. 2018;

11. Kettunen C, Nemecek J, Wenger O. Evaluation of low immunization coverage among the Amish population in rural Ohio. Am J Infect Control. 2017;45(6):630-4.

12. Mapatano MA, Kayembe K, Piripiri L, Nyandwe K. Immunisation-related knowledge, attitudes and practices of mothers in Kinshasa, Democratic Republic of the Congo. South African Fam Pract. 2008;50(2):61.

13. Bofarraj MAM. Knowledge, attitude and practices of mothers regarding immunization of infants and preschool children at Al-Beida City, Libya 2008. Egypt J Pediatr Allergy Immunol. 2011;9(1).

14. Masika CW, Atieli H, Were T. Knowledge, perceptions, and practice of nurses on surveillance of adverse events following childhood immunization in Nairobi, Kenya. Biomed Res Int. 2016;2016.

15. Adil MM, Zubair M, Alam AY, Khan SM, Ishtiaque B. Knowledge of mothers about childrens immunization status in the urban areas of Islamabad. Rawal Med J. 2009;34(1):33-5. 